\title{
MODEL OF SUCCESSFUL STRATEGY EXECUTION: REVISING THE CONCEPT
}

\author{
Joanna Radomska \\ Wroclaw University of Economics, Wroclaw, Poland \\ E-mail: joanna.radomska@ue.wroc.pl
}

\begin{abstract}
The purpose of this research is to examine the relationship between the elements of the Eight "S" model that affect strategic implementation and results achieved by companies. The main research question, to which the author sought an answer, was whether there was a relationship between individual elements that affect strategy implementation and the effects it brings in revenue growth. The survey covered 200 of the best-ranked Polish companies (where revenues constituted one of the ranking criteria) where the level of strategic implementation was considered satisfactory. Testing of the research hypotheses has shown that the factors defined as Resources and Shared Values have a minor impact on the strategy implementation. The research also has shown that there is an additional element that could be incorporated into the model - the system of informal communication. In addition, the paper describes the interrelations between elements of the model.
\end{abstract}

Key words: implementation model, informal communication, strategy execution.

\section{Introduction}

The problem of strategy execution is a timely issue and subject to many in-depth studies (Huber, 2011: 49) mainly due to the fact that there is still little known about the tools and methods supporting the process (Morgan, Levitt and Malek, 2007). Although many concepts and theoretical models have been developed, strategic management theory is still looking for answers regarding their usability and their associated implications (Hitt, Freeman, Harrison, 2006).

One of these models is the Eight "S" model. This model focuses on factors that support an effective execution of the strategy (Higgins, 2005: 3-13). The aim of this study is to examine the impact of these factors on implementation of development concept in companies. For this purpose, it was assumed that one of the criteria indicating the efficiency is the revenue growth rate and the trends associated with it (decline, growth, stagnation). The revenue growth was described as an increase of a company's sales when compared to a previous year's revenue performance. These trends can be considered as measures of the actions taken.

\section{Problem of Research}

As indicated by the results of many studies, the strategy execution process is much more difficult than the formulating stage. Surprisingly significant number of managers devote less attention to strategy implementation than to formulation (Hanley, 2007: 17). This is because the conceptual stage is often supported by various tools and expert opinions, while the execution process requires the combination of many, sometimes inconsistent elements and the elimination of internal and external factors. The strategy development process consists of selecting appropriate options and ensuring their effectiveness, while the execution process requires that 
Joanna RADOMSKA. Model of Successful Strategy Execution: Revising the Concept

PROBLEMS

OF MANAGEMENT

IN THE $21^{\text {st }}$ CENTURY Vol. 9, No. 3, 2014

214

these options are effectively implemented. Without effective implementation, understood as a process of putting plans and strategies into action, it is not possible for an organization to evolve (Kathuria, 2012: 6). In addition, this process requires adequate quality of visibility, leverage and responsiveness (Veth 2006:31). It is certain that if insufficient time and energy are devoted to strategy implementation, then this will result in poor company performance and weaken the competitive position. On the other hand, the rate of change both in the environment and within the organization, resulting in subsequent adjustments and modifications of the strategy, means that implementation becomes a critical step in the strategic management process. Powell (2004: 77-80) indicates the existence of the phenomenon known as "execution holes", i.e. a situation when the strategy is not effectively implemented despite elimination of all rational barriers. The reasons seem to be irrational and hence cannot be explained by any economic law or behavioural heuristic. That is why it's important to search for the correct models and tools as these may be a source of managerial inspiration. The Eight " $\mathrm{S}$ " model is based on the concept introduced by Peters and Waterman (1982). This model was subsequently supplemented by Higgins (2005: 3-13) by adding an eighth element i.e. Strategic Performance, which draws managers' attention to the results achieved. According to the author, this element can have many forms, ranging from the setting of strategic goals to result measurement. The basic assumption for this model is that the execution of different strategies requires various types of organizational structures, systems, management styles, staff, resources and shared values. Therefore, the elements described above should be analysed in detail.

\section{Strategy and Purpose}

Many authors draw attention to the content of the strategy and the manner of its formulation as the factors which affect the possibility of its implementation. As mentioned by Frigo (2003: 8-9), even a well-organized implementation process will lead to poor performance, if it aims at achieving improper objectives and making wrong decisions. Also, Martin (2010: 53-64) points out that in many cases the cause of company's problems is not poor execution, but the strategy itself. Moreover, he substantiates the lack of grounds in separating these two processes by the fact that it is not possible to determine clearly when implementation begins. Thus, introducing a distinction between these two stages may result in chaos and confusion. It seems therefore, reasonable to emphasize the feedback between these two aspects and their mutual interactions.

\section{Structure}

The fact that the structure affects the efficiency of the implementation activities was confirmed by extensive studies, in which a significant number of respondents indicated this factor as a key element responsible for the gap between the strategy and its implementation (Lepsinger, 2006: 56-67; Hrebiniak, 2008: 2). Getz and Lee (2011: 303-305) also indicate the necessity to create an organizational architecture that is consistent with the strategic architecture. As some authors have said, the larger the company and its organizational structure, the greater the possible level of employee participation at the strategy execution stage in individual departments, business units and project groups - therefore the strategy is then more partial than comprehensive (Ashmos et al., 2002: 189-206). A large and more complex organizational structure requires a greater involvement of middle and operational level managers. As shown by research results, this is a prerequisite for effective strategic implementation and achievement of better results in the competitive struggle (Ogbeide, Harrington, 2011: 733). 


\section{Systems and Processes}

As emphasized by Coon and Wolf (2005: 29-30), it is important to align processes and systems to reinforce the desired behaviours and outcomes. In particular, this involves searching for a link between the implemented strategy and other processes taking place in the organization. It is essential especially for strategic control and for monitoring the strategic execution process (Julian, 2002: 115-139). Formalization of procedures and processes not only brings order to decision-making, but also introduces a certain rationality, which contributes to the efficiency and effectiveness of the actions taken (Betz, 2001: 60). It is also worth mentioning the incentive system, which should be linked with the strategy execution stage, as the determinant of the implementation progress and a tool for its regular control (Hrebiniak 2005). As shown by the research results (Radomska, 2013: 80-92), the use of formal tools and systems for measuring the degree of strategic goal realization allows them to be linked with the payroll-based incentive system. Thus, it is a benefit resulting from formalization of the strategy implementation, which at the same time enables ongoing monitoring of strategic initiatives.

\section{Style (leadership/management style)}

Many authors draw attention to the impact of management style on employee involvement in the strategy execution, as they are responsible for defining the strategic guidelines and rules that determine the perception of the strategy at all levels of the organization (Boomer, 2007: 24). Thus, managements' task is to eliminate the gap between the strategy and employees everyday activities, as well as to take actions aimed at effective communication of the interrelation between operational issues and the pursuit of the strategic direction chosen (Becher, 2005: 11). Results of many studies point out the issues associated with the unregulated decision-making process and the improper perception of the sources of unsuccessful strategy implementation among managers (Mezias and Starbuck, 2003: 3-17; Zajac and Bazerman, 1991: 37-56). This is also indicated by Haudan (2007: 38-39), who emphasizes that the task of leaders should include creating an aligned mental model, promoting individual ownership of the whole or cultivating aligned behaviours. The surveys show that a large majority of the respondents indicate the existence of an imaginary line dividing employees into creators and executors of the strategy (How Hierachy, 2010: 74-75). Formulation of a development concept is perceived most often as a creative task and therefore is assigned to top management (Raffoni, 2003: 1-3), while its execution does not add enough splendour (G. Cocks, 2010: 260). Foster and Browne (1996) mention that implementation is an area delegated generally to mid-level managers. Therefore, the leaders' task is to take measures aimed at eliminating this informal division in order to assign the status of a common goal to the strategy execution.

\section{Staff}

Companies that achieve good implementation results can effectively focus employees attention on the tasks associated with achieving strategic objectives by giving them decisionmaking powers and establishing a clear system for assessing the effects (Henman, 2010-11: 30). This can be done through the participation of a large group of employees at the planning stage. In that case the link between their actions and the strategic development concept can be emphasized (Hapst, 2008: 19). It also brings a significant improvement in communication during implementation (Viljoen \& Dann, 2000). A drop in employee involvement in performing operational functions is observed especially in the situations where they could not participate actively in the creative stage (Hubbard et al., 1996). That is because employee resistance is the aspect responsible for failure when executing any initiatives or changes. 
Joanna RADOMSKA. Model of Successful Strategy Execution: Revising the Concept

$\begin{array}{r}\text { PROBLEMS } \\ \text { OF MANAGEMENT } \\ \text { IN THE 21 }{ }^{\text {st }} \text { CENTURY } \\ \text { Vol. 9, No. 3, } 2014 \\ \hline 216\end{array}$

\section{Resources}

The results of the studies indicate that resource constraints are often mentioned as an obstacle to strategy execution (How Hierarchy, 2010). Morgan (2010-11: 16-17) observes that there is a problem with the allocation of resources and their planned use. Noble (1999: 21) indicates the importance of pooling resources in organizing the implementation effort. It seems essential to pay attention to proper budget construction, taking resource constraints into account. The proper usage of available resources is also essential for successful implementation (Thompson et al., 2006).

\section{Shared Values}

Many authors indicate the role of the consistency between the strategic objectives and the principles and values of the organization as crucial for implementing strategy (Batley, 1998: 309-312; Becker, 1993: 30-34; Bamber et al., 1999: 162-181, Sabourin, 2012: 53-59), especially in the context of managerial actions (Lepsinger, 2006: 56-57). The focus on a set of core values is closely associated with an appropriate organizational culture and requires that such actions are assigned with the status of importance comparable with the focus on the performance (Ruhmann, 2011: 3). Pateman (2008: 12) defines the phenomenon known as "value gap", i.e. defining the necessary changes, based on the organization's vision, which are essential to preserve the consistency between the actions and the expected results. An important issue worth emphasizing is that employees should be aligned with the vision, values and strategy, while through their involvement in the strategy implementation process they should be able to perceive the real consequences of implementing this joint vision of development (Khadem, 2008: 29-30). Fitting these actions competently into the culture of the organization is also significant (Varon, 2002: 4).

\section{Strategic Performance}

Becher (2005: 11) draws attention to the need for measuring the achievements of implementation in a way that allows for both identification of emerging issues and areas for further development. The issue of measuring progress in the strategy implementation turns out to be very important. Many researchers deal with the problems associated with methods of performing such measurements by considering both financial and non-financial factors. As indicated, the second type of metrics is more closely associated with strategic initiatives, although it also allows for focusing on elements which are more difficult to measure. On the other hand, the use of measurable tools, such as Balanced Scorecard, eliminates some of the communication problems and improves the strategy implementation process (Frigo, 2002: 8-9). Many authors have investigated the issues related to performance measurement and management systems, as well as problems associated with their inadequate use (Schneier et al., 1992: 279-282; Mohrman et al., 1989). Such studies often focus on measurement of issues that are too narrow or too general, and may not be always related to the strategy implemented (Schneier et al., 1991: 247-260). Li et al. (2008: 1-46) writes about different perspectives of such systems, mentioning the process perspective, action perspective and hybrid perspective. Rho et al. (2001: 89-97) also introduces the gap perspective and emphasizes the gap variables and the inconsistency between strategy and execution. Sushil and Srivastava (2013: 554-582) suggest that organizations should not only implement both financial and non-financial metrics, but also consider structural relations -the participants and the situation of a particular organization. 


\section{Methodology of Research}

General Background of Research

The study was aimed at identifying barriers to strategic execution, as well as elements that support implementation. The surveyed companies, due to their presence in prestigious rankings, can be considered as representatives of the group of entities that have been rather successful in the implementation activities. The results indicate that they have managed to execute the adopted strategy at an average level of $74 \%$, which can be regarded as satisfactory. So, the companies participating in the survey do not have significant problems with implementation or are able to effectively introduce appropriate remedies aimed at eliminating potential barriers. It is assumed that the best indicator that determines the company's performance is the revenue growth rate.

\section{Sample of Research}

The group of respondents included managers of 200 companies that have been operating for at least 5 years and which are listed among the 500 largest Polish companies according to "Polityka" weekly magazine (101 entities) and in "Forbes Diamonds 2013" ranking (99 companies). The first ranking takes into account sales revenue, total revenue, gross and net profit, as well as employment level. The "Diamonds" list included the companies with the fastest increase in value. The group of respondents included 68 small businesses (up to 49 employees), 63 medium-sized companies (50-249 employees) and 69 large enterprises (employing over 250 people).

\section{Instrument and Procedures}

The study was conducted using the PAPI (Paper and Pencil Interview) technique - the survey was carried out with the use of a method based on collecting the data in an open (overt) and standardized way. The questions in the questionnaire were of nominal nature (the respondents declared the existence of specific obstacles) and of ordinal variable nature (the respondents indicated the strength of their impact in a 5-point scale). The V-Cramer's coefficient was determined for nominal variables. It measures the strength of the relationship between them.

\section{Research Results}

The following research hypotheses have been proposed:

H1: There is a relationship between the internal inconsistency in the strategy implemented and the results achieved by the company.

$\mathrm{H} 2$ : There is a relationship between the organizational structure not matched to the strategy implemented and the results achieved by the company.

H3: There is a relationship between the use of formal systems for supporting the strategy implementation and the results achieved by the company.

$\mathrm{H} 4$ : There is a relationship between the transfer of the responsibility for implementation activities to leaders at various levels of the organizational structure and the results achieved by the company.

H5: There is a relationship between the inclusion of a large group of employees in the strategy development stage and the results achieved by the company.

H6: There is a relationship between the allocation of insufficient funds for the strategy execution and the results achieved by the company. 
Joanna RADOMSKA. Model of Successful Strategy Execution: Revising the Concept

PROBLEMS

OF MANAGEMENT

IN THE $21^{\text {st }}$ CENTURY Vol. 9, No. 3, 2014

218

H7: There is a relationship between the identification of employees with the strategy implemented and the results achieved by the company.

H8: There is a relationship between the use of Balanced Scorecard and the results achieved by the company.

H9: There is a relationship between the use of informal communication and the results achieved by the company.

Detailed results are presented in the Table 1.

Table 1. Hypotheses and research results.

\begin{tabular}{lll}
\hline Hypothesis & V-Cramer & p-value \\
\hline $\mathrm{H} 1$ & 0,294 & 0.018 \\
\hline $\mathrm{H} 2$ & 0,321 & 0.006 \\
\hline $\mathrm{H} 3 \mathrm{a}$ & 0,297 & 0.016 \\
\hline $\mathrm{H} 3 \mathrm{~b}$ & 0,397 & 0.000 \\
\hline $\mathrm{H} 4$ & 0,360 & 0.001 \\
\hline $\mathrm{H} 5$ & 0,414 & 0.000 \\
\hline $\mathrm{H} 6$ & 0,229 & 0.174 \\
\hline $\mathrm{H} 7$ & 0,190 & 0.420 \\
\hline $\mathrm{H} 8$ & 0,397 & 0.000 \\
\hline $\mathrm{H} 9$ & 0,305 & 0.011 \\
\hline
\end{tabular}

The results obtained when testing Hypothesis 1 indicate the existence of a weak statistical relationship (0.294) between the revenue growth rate and the internal inconsistency of the strategy implemented (inconsistent vision, objectives, schedule or budget). It should be emphasized that only 21 entities $(10.7 \%)$ from the surveyed sample confirmed the existence of this problem associated with implementation. A small number of them (only 6) declared a decline in revenues, while the same number - stagnation. The answers obtained verify Hypothesis 1 positively, and thus confirm the existence of a relationship between the vaguely formulated strategy and the revenue growth rate. However, a thorough analysis of the answers does not allow for the generalization of conclusions concerning the direction of this relationship.

An average statistical relationship was obtained for Hypothesis 2, which indicates the existence of a dependence $(0,321)$ between the organizational structure not matched to the requirements associated with the strategy implemented and the revenue growth rate. 27 entities (less than 14\%) declared that this element had a negative impact on results, which represents a relatively small percentage.

Hypothesis 3 was divided into two parts - H3a concerns the use of budgeting and task scheduling as tools supporting the strategy implementation. The result obtained (0.297) proves that there exists a weak statistical relationship between these elements and the results achieved by the company. A slightly higher correlation (0.397) was obtained for the Hypothesis H3b by 
examining the association with the use of an incentive system, in which the level of employee remuneration depends on the degree of achievement of strategic objectives. In both cases, the use of formal systems was declared by $69.7 \%$ of the companies, while an increase in revenues was recorded in $77.9 \%$ of the entities that use budgeting and scheduling, as well as in $81.6 \%$ of the companies that use incentive systems designed to support the strategy implementation. Both results verify this hypothesis positively.

An average statistical relationship $(0,36)$ was obtained also for Hypothesis 4 , thus confirming the dependence between the transfer of responsibility for implementation activities to leaders at various levels of the organizational structure and the results achieved by the company. Moreover, this was confirmed by positive answers received from 139 companies, which constitutes a significant percentage (71\%). At the same time, $82.7 \%$ of them reported an increase in revenues and therefore this hypothesis can be verified positively.

The highest value of dependence (0.414) was obtained for Hypothesis 5, which confirms the existence of a statistical correlation between the inclusion of a large group of employees in the strategy development stage and results achieved by the company. Interestingly, this solution was used by less than half of the companies surveyed (47.9\%), while $86.1 \%$ of them reported an increase in the revenue growth rate. Nevertheless, this hypothesis should be accepted.

With respect to Hypothesis 8 , the existence of an average statistical relationship $(0,397)$ between the use of Balanced Scorecard and the results achieved by the company was proved. However, only $36.7 \%$ of the entities use this tool, while for $90.27 \%$ of these resulted in an increase in the revenue growth rate. Therefore, the hypothesis can be accepted.

Hypotheses 6 and 7 are not statistically significant as the level of correlation is weak $(0,229$ and 0,19$)$, so there is no basis for accepting them. Thus, the existence of a relationship between the allocation of adequate funds for the strategy implementation as well as the identification of employees with the development concept and the results achieved by the company was not proved. This provides a basis for proposing Hypothesis 9 and introducing another element of the Eight "S" model, i.e. the system of informal communication. This element was used in $59.7 \%$ of the entities, which indicates that it may be considered a relatively important factor, especially due to the fact that as much as $79.5 \%$ of them achieved an increase in the revenue growth rate. The result obtained (0.305) indicates the existence of an average statistical relationship between the use of informal communication and the results achieved by the company, which supports this hypothesis.

\section{Discussion}

The research results showed that inconsistencies in the strategy have a negative impact on the results achieved by a majority of the companies. As confirmed by other researchers, it is connected with the conflicting priorities or vague strategy (Hrebiniak 2006) and the lack of clarity in strategy formulation (Grundy 2012). As indicated by the conducted research, most organizations pay attention to the organizational structure supporting the strategy implementation. It is the element considered while selecting the development concept in order to eliminate the negative consequences resulting from possible mismatch. Such findings also support the results of Brenes, Mena and Molina (2008). There may be also drawn a conclusion that the transfer of the responsibility for implementation activities to leaders at various levels of the organizational structure is important from the viewpoint of the results obtained. As mentioned by Forrester (2000), the empowerment, and the decision power is supposed to support the strategy execution. The research results proved that although the level of the employee participation as a natural support for the strategy implementation is relatively low, it brings positive results.

There have also been indicated positive implications associated with the introduction of Balanced Scorecard to the enterprise management system, as it is one of the methods that improves the strategy implementation results. It was already mentioned in various studies (Thompson and Mathys, 2008; Perkins, Grey, Remmers, 2014). It can be also stated, that the 
Joanna RADOMSKA. Model of Successful Strategy Execution: Revising the Concept

$\begin{array}{r}\text { PROBLEMS } \\ \text { OF MANAGEMENT } \\ \text { IN THE 21 } 1^{\text {st }} \text { CENTURY } \\ \text { Vol. 9, No. 3, } 2014 \\ \hline 220\end{array}$

the

research showed that it isn't necessary for employees to share the underlying values in order for the strategy to be implemented. It is sufficient to take actions that aim at involving employees in the strategic management process - mainly due to the communication benefits.

\section{Conclusions}

The main limitation of the described surveys, due to their nature, was the subjectivity of answers. It prevented the obtaining of unequivocal declarations required to identify specific types of barriers. Therefore, more in-depth surveys should be conducted, covering a wider group of respondents, in order to obtain a more complete picture reflecting companies performance. In addition, the specific character of the Eight "S" model should be examined in companies of various sizes. However, as the research has shown, the factors defined as Resources and Shared Values have a minor impact on the strategy implementation. There is an additional element that could be incorporated into the model - the system of informal communication.

\section{Acknowledgements}

The project was financed with the funds of The National Science Centre based on the decision no. DEC-2011/03/B/HS4/04247.

\section{References}

Ashmos, D., \& Duchon, D., \& McDaniel, R., \& Huonker, J. (2002). What a mess! Participation as a simple managerial rule to 'complexify' organizations. Journal of Management Studies, 39 (2), 189-206.

Bamber, C., \& Sharp, J., \& Hides, M. (1999). Factors affecting successful implementation of total productive maintenance: A UK manufacturing case study perspective. Journal of Quality in Maintenance Engineering, 5 (3), 162-181.

Batley, T. (1998) Management training of professional engineers in New Zealand. Journal of European Industrial Training, 22 (7), 309-312.

Becher, J. (2005). Operational alignment: Bridging the gap between strategy and execution. Business Performance Management, March, 11.

Becker, S. (1993). TQM does work: Ten reasons why misguided efforts fail. Management Review, 82 (5), 30-34.

Betz, F. (2001). Executive strategy. Strategic Management and Information Technology. John Wiley \& Sons, New York, 154.

Boomer, G. (2007). Strategy: Execution and alignment. Accounting Today, May 21-June 3, 24.

Bovey, W., \& Hede, A. (2001). Resistance the organizational change: The role of cognitive and affective processes. Leadership \& Organization Development Journal, 22, 372-382.

Brenes, E., Mena, M., Molina, G. (2008). Key success factors for strategy implementation in Latin America. Journal of Business Research, 61, 595.

Cocks, G. (2010). Emerging concepts for implementing strategy. The TQM Journal, 22(3), 260.

Coon, B., \& Wolf, S. (2005). The Alchemy of Strategy Execution. Employment Relations Today, 32(3), 29-30.

Forrester, R., (2000). Empowerment: Rejuvenating a potent idea. The Academy of Management Executive, 14,69 .

Foster, J., \& Browne, M. (1996). Principles of strategic management. Macmillan Education, South Yarra, 47.

Frigo, M. (2002). Nonfinancial performance measures and strategy execution. Strategic Finance, August, 8-9.

Frigo, M. (2003). Strategy or execution? Strategic Finance, March, 9.

Getz, G., \& Lee, J. (2011). Why your strategy isn't working. Business Strategy Series, 12 (6), 303-305.

Grundy, T. (2012). Demystifying strategy: How to become a strategic thinker. Kogan Page, London, Philadelphia, 7. 
Hanley, C. (2007). The Execution Challenge: Translating Strategy into Action. Bank Accounting \& Finance, October - November, 17.

Hapst, G. (2008). Strategy Execution. Go with a complete program. Leadership Excellence, September, 19.

Haudan, J. (2007). Successful strategy execution takes people - not paper. Employment Relations Today, 33 (4), 38-39.

Henman, L. (2010-11). Turn great strategy into great execution. American Management Association, Winter, 30.

Higgins, J. (2005), The Eight 'S' of Successful Strategy Execution. Journal of Change Management, $5(1), 3-13$.

Hitt, M., Freeman, E., \& Harrison, J. (2006). The Blackwell handbook of strategic management. Blackwell Publishing, Oxford, 123-135.

How Hierarchy Can Hurt Strategy Execution. (2010). Harvard Business Review, July-August, 74-75.

Hrebiniak, L. (2005). Making strategy work: Leading effective execution and change. Pearson Education, Upper Saddle River.

Hrebiniak L. (2006). Obstacles to effective strategy implementation. Organizational Dynamics, 35 (1), 17.

Hrebiniak, L. (2008). Making strategy work: Overcoming the obstacles to effective execution. Ivey Business Journal Online, 72, 2.

Hubbard, G., Pocknee, G., \& Taylor, G. (1996). Practical Australian strategy. Prentince - Hall, Brookville.

Huber, A. (2011). Effective strategy implementation. Conceptualizing firm's strategy implementation capabilities and assessing their impact on firm performance. Gabler Verlag, Wiesbaden, 49.

Julian, S., Scifres, E. (2002). An interpretive perspective on the role of strategic control in triggering strategic change. Journal of Business Strategies, 19 (2), 115-139.

Kathuria, R. (2012). Strategy execution. How thinking strategically will benefit your business, Smart Business Houston, January, 6.

Khadem, R. (2008). Alignment and follow-up: Steps to strategy execution. Journal of Business Strategy, 29 (6), 29-30.

Lepsinger, R. (2006). Surveying the gap: Nearly half of all leader see a disconnect between strategy and execution. Business Credit, October, 56-57.

Li, Y., Guohui, S., \& Eppler, M. (2008). Making strategy work: A literature review on the factors influencing strategy implementation. ICA Working Paper, 2, 1-46.

Martin, R. (2010). Drawing a line between strategy and execution almost guarantees failure. Harvard Business Review, 7-8, 53-64.

Mezias, J., \& Starbuck, W. (2003). Studying the accuracy of managers' perceptions: The odyssey continues. British Journal of Management, 14, 3-17.

Mohrman, A., Resnick-West, S., \& Lawler, E. (1989). Designing performance appraisal systems. San Francisco: Jossey-Bass, 165-176.

Morgan, J. (2010-11). Strategy execution. A Four-Step Process. American Management Association, Winter, 16-17.

Morgan, M., Levitt, R., \& Malek, W. (2007). Executing your strategy how to break it down and get it done. Harvard Business School Press.

Noble, C. (1999). Building the strategy implementation network. Business Horizons, November - December, 21.

Ogbeide, G., \& Harrington, R. (2011). The relationship among participative management style, strategy implementation success, and financial performance in the foodservice industry. International Journal of Hospitality Management, 23 (6), 733.

Pateman, A. (2008). Linking strategy to operations: Six stages to execution. Business Performance Management, December, p. 12.

Peters, T., \& Waterman, R. (1982). In search of excellence. New York, Harper \& Row.

Perkins, M., Grey, A., \& Remmers, H. (2014). What do we really mean by "Balanced Scorecard"? International Journal of Productivity and Performance Management, 63 (2), 166.

Powell, T. (2004). Strategy, execution and idle rationality. Journal of Management Research, 4 (2), August, $77-80$.

Radomska, J. (2013). Formalisation in strategy implementation - the key to success or an unnecessary limitation? International Journal of Contemporary Management, 3 (12), 80-92. 
Joanna RADOMSKA. Model of Successful Strategy Execution: Revising the Concept

PROBLEMS

OF MANAGEMENT

IN THE $21^{\text {st }}$ CENTURY Vol. 9, No. 3, 2014

222

Raffoni, M. (2003). Three keys to effective execution. Harvard Management Update, 8 (2), 1-3.

Rho, B., Park, K., \& Yu, Y. (2001). An international comparison of the effect of manufacturing strategyimplementation gap on business performance. International Journal of Production Economics, 70, 89-97.

Ruhmann, J. (2011). Strategy execution. Make it your core competency. Leadership Excellence, August, 3.

Sabourin, V. (2012). Through the lenses of strategy execution: Obstacles in engineering management. Leadership and Management in Engineering, 12 (2), 53-59.

Schneier, C., Shaw, D., \& Beatty, R. (1991). Performance measurement and management: A tool for strategy execution. Human Resource Management, 30 (3), 279-282.

Schneier, C., Beatty, R., \& Shaw, D. (1992). Why measure the CEO's performance. In: Niehaus, R., \& Price, K. (Ed.). Bottom line results from human resource planning. New York: Plenum, 247-260.

Srivastava, A., \& Sushil, (2013). Modelling strategic performance factors for effective strategy execution. International Journal of Productivity and Performance Management, 62 (6), 554-582.

Thompson, A., Gamble, J., \& Strickland, A. (2006). Strategy: Winning in the marketplace: core concepts, analytical tools, cases (2nd edition), McGraw-Hill/Irwin, Boston.

Thompson, K., \& Mathys, N. (2008). The aligned balanced scorecard: an improved tool for building high performance organizations. Organizational Dynamics, 37 (4), 378-93.

Varon, E. (2002). Implementation is not for the meek. CIO, 16 (4).

Veth, G. (2006). Building the platform for strategy execution. DM Review, 31.

Viljoen, J., \& Dann, S. (2000). Strategic management: Planning and implementing successful corporate strategies. Pearson Education, Sydney.

Waterman, R. (1982). The seven elements of strategic fit. Journal of Business Strategy, 71.

Zajac, E., \& Bazerman, M. (1991). Blind spots in industry and competitor analysis: Implications of interfirm (mis) perceptions for strategic decisions. Academy of Management Review, 16, 37-56.

Advised by Andrzej Kaleta, Wroclaw University of Economics, Wroclaw, Poland

Received: October 07, 2014

Accepted: December 10, 2014

Joanna Radomska

PhD., Assistant Professor, Wroclaw University of Economics, Komandorska 118/120,

53-345 Wroclaw, Poland.

E-mail: joanna.radomska@ue.wroc.pl

Website: http://www.ue.wroc.pl 